\title{
Modeling and Simulation of STATCOM for a power system network using MATLAB/SIMULINK
}

\author{
Javid Akhtar ${ }^{1}$, Sinto george ${ }^{2}$ \\ Dept of Electrical and Electronics Engineering, Ghousia College of Engineering, Ramanagaram, \\ Karnataka, India
}

\begin{abstract}
Nowadays, the proliferation of non-linear loads (especially power electronics equipment) leads to deterioration of the quality of voltage waveforms at the point of common coupling (PCC) of various consumers. In view of the wide spread use of harmonics-sensitive electronic equipment, power conditioning equipment is becoming more important for both electric utilities and their customers. With rapid development of power semiconductor devices in power and control circuits, a new generation of equipments that help maintaining a good level of power quality, namely active power filters, has been developed. Theirs advantages over conventional means are more flexibility and very fast control response. This paper aim to present the actual status of active power filters based on state of the art power electronics technology.

A STATCOM or Static Synchronous Compensator is a regulating device used on alternating current electricity transmission networks. It is based on a power electronics voltage-source converter and can act as either a source or sink of reactive AC power to an electricity network. If connected to a source of power it can also provide active AC power. It is a member of the FACTS family of devices. STATCOM has no long term energy support in the DC Side and can not exchange real power with the ac system; however it can exchange reactive power. Also, in principle, it can exchange harmonic power too. But when a STATCOM is designed to handle reactive power and harmonic currents together it gets a new name - Shunt Active Power Filter. So a STATCOM handles only fundamental reactive power exchange with the ac system. In this paper, the present work is aimed at the study of a STATCOM or Static Synchronous Compensator - as it is otherwise called - as a solution to these (dynamic compensation of reactive and harmonic currents) power quality issues
\end{abstract}

\section{INTRODUCTION}

The issue of power factor improvement and harmonic compensation is well known in electrical engineering. A major area of research in electrical engineering is to make a system wherein the current absorbed from the electrical utility is almost purely sinusoidal and is in phase with the voltage. The need for this is the losses incurred at the transmission otherwise and also the unnecessary expense incurred to have systems (generators, transformers and transmission lines) that can support higher currents. Though it had been a practice to use capacitors, switched capacitor banks, synchronous condensers and several other means to achieve power factor improvement till some time back, problems surfaced with more and more electronic and power electronic equipments being put to use - since now harmonics also had to be tackled. Besides the fact that some of the earlier equipments could not compensate for harmonics, some (like capacitors) others caused issues like resonance. Also, even without the problem of harmonics, the research was to develop systems that can dynamically compensate for reactive current under varying load conditions. The present work is aimed at the study of a STATCOM or Static Synchronous Compensator - as it is otherwise called - as a solution to these (dynamic compensation of reactive and harmonic currents) power quality issues.

In the present study, the synchronous reference frame strategy is used to generate current reference for compensation and conventional PI controllers are used for control. The synchronous reference frame strategy utilizes co-ordinate transformations to separate the reactive and harmonic content in the load current. The design of the closed loop controllers is kept simple by modeling them as first order systems.

The simulation studies showed good results with the reactive current compensation giving almost ideal result of near unity power factor and harmonic currents getting compensated to a larger extent. As expected, harmonic currents could not be completely compensated due to the fact that the inverter produces the output voltage only on a time-averaged sense. However, the Total Harmonic Distortion [THD] readings showed considerable reduction in harmonics. This thesis deals with the modeling and simulation of Static Synchronous Compensators, STATCOM, a shunt compensation device, from the family of Flexible Alternating Current Transmission Systems, FACTS. The STATCOM is a solid-state voltage source converter which is tied to a transmission line. A STATCOM injects an almost sinusoidal current, of variable magnitude, at the point of connection. This injected current is almost in quadrature with the line voltage, thereby emulating an inductive or a capacitive reactance at the point of connection with the transmission line. 


\section{METHODOLOGY}

Non linear loads like variable speed drives, UPS and all kinds of rectifiers draw a non-sinusoidal current from the network. Therefore they can be considered to be harmonic current sources. Shunt active filters work as a current source which, when properly designed and controlled, produces harmonic currents having opposite phase than those harmonic currents produced by the non linear loads. When such a shunt active filter is connected parallel with a non linear load its harmonic currents are compensated and the network is loaded with almost fundamental current only.

\section{A. NEED OF FACTS DEVICES}

The main advantages of using FACTS devices are

- Better utilization of existing transmission system assets

- Increased transmission system reliability and availability

- Increased dynamic and transient grid stability and reduction of loop flows

- Increased quality of supply for sensitive industries

- Environmental benefits

There is a better utilization of existing transmission system assets. Building new transmission lines to meet the increasing electricity demand is always limited economically and by environmental constraints and FACTS devices meet these requirements using the existing transmission systems. Increase in transmission system reliability and availability as FACTS devices mitigate the effects of faults and make supply of electricity more securely by reducing the number of trips. Increase in dynamic and transient grid stability and reduction of loop flows is achievable as FACTS devices can stabilize transmission systems with higher energy transfer capability and reduction in risks of line trips. There is an increased quality of supply for sensitive industries because FACTS devices can provide the required quality of supply to high quality electricity supply where loss of supply or voltage dips leading to interruptions in manufacturing processes resulting in high economic loss could be overcome. Furthermore FACTS provide in terms of environmental benefits as they do not contain harmful materials nor produce waste or pollutants. In fact FACTS devices help to distribute electricity more economically through better utilization of existing installations thereby reducing the need for additional transmission lines

\section{B. FACTS DEVICES}

As previously mentioned FACTS devices are power electronic based equipments, which are used for the dynamic control of voltage, impedance and phase of high voltage AC transmission lines. There are basically two types of FACTS controllers; Thyristor-based controllers and converter-based controllers.

Thyristor-based FACTS Controllers (including Static Var Compensator or SVC, the ThyristorControlled Series Capacitor or TCSC, and the Thyristor-Controlled Phase Angle Regulator or TCPAR) employ conventional Thyristors (i.e., those having no intrinsic turn-off ability) to control one of the three parameters determining power transmission, voltage (SVC), transmission impedance (TCSC), and transmission angle (TCPAR). The major members of this group, the SVC and TCSC, have a common characteristic in that, the necessary reactive power required for the compensation is generated or absorbed by conventional capacitor or reactor banks, and the Thyristor switches are used only for the control of the combined reactive impedance these banks present to the AC system. The tap-changer-based regulators do not inherently need a capacitor or reactor; however, they may do so if the AC system is unable to supply the reactive power needed to support their operation. Consequently, conventional Thyristor-controlled compensators, the SVC and TCSC, present variable reactive impedance to, and thus act indirectly on, the transmission network. The SVC functions as a controlled shunt reactive admittance that produces the required reactive compensating current. Thus, the attainable reactive compensating current is a function of the prevailing line voltage. The TCSC is controlled reactive impedance in series with the line for the purpose of developing a compensating voltage. Thus, the attainable reactive compensating voltage is a function of the prevailing line current. Neither the SVC nor the TCSC exchanges real power with the ac system (except for losses). The Thyristor - based controllers are shown in fig 1 below according to their function with respect to the power flow 


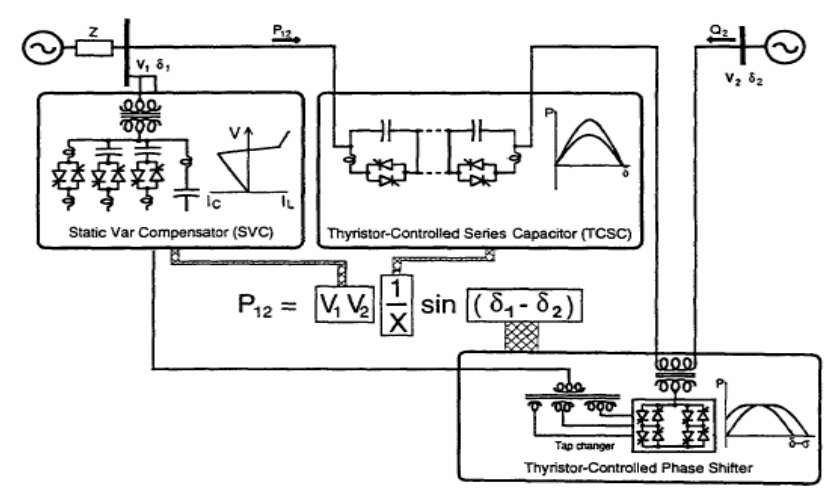

Fig 1 Thyristor - based controllers

\section{STATIC SHUNT COMPENSATION}

A STATCOM or Static Synchronous Compensator is a regulating device used on alternating current electricity transmission networks. It is based on a power electronics voltage-source converter and can act as either a source or sink of reactive AC power to an electricity network. If connected to a source of power it can also provide active AC power. It is a member of the FACTS family of devices. Static shunt compensation is used to influence the natural electrical characteristics of the transmission line to increase the steady-state transmittable power and to control the voltage profile along the line. In principle, all shunt-type controllers inject additional current into the system at the point of common coupling (PCC) through the means of a voltage source converter. The impedance of the shunt controller, which is connected to the line voltage, causes a variable current flow, and hence represents an injection of current into the line. As long as the injected current is in phase quadrature with the line voltage, the shunt controller only supplies or consumes variable reactive power. The ultimate objective of applying reactive shunt compensation in a transmission system is to increase the transmittable power capability from the generator to the load, which is required to improve the steady-state transmission characteristic as well as the stability of the system .This chapter provides the basic operating principles, characteristics and requirements of static shunt compensators.

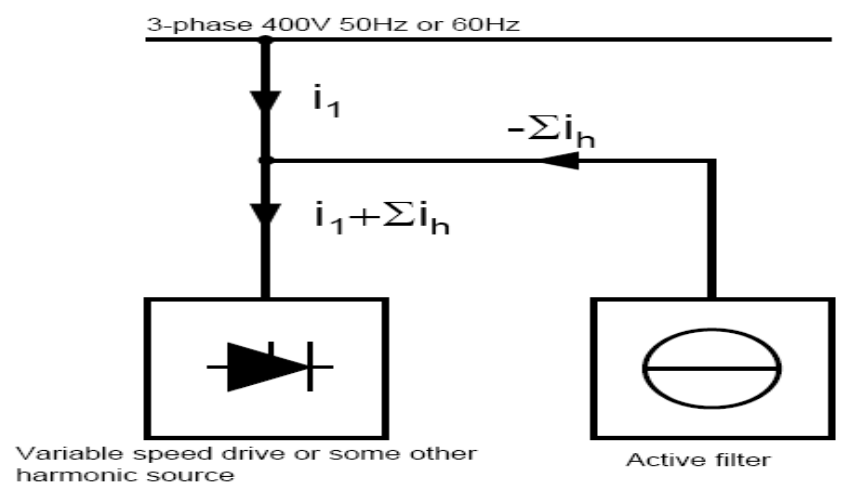

Fig 2 Non linear load with shunt active filter

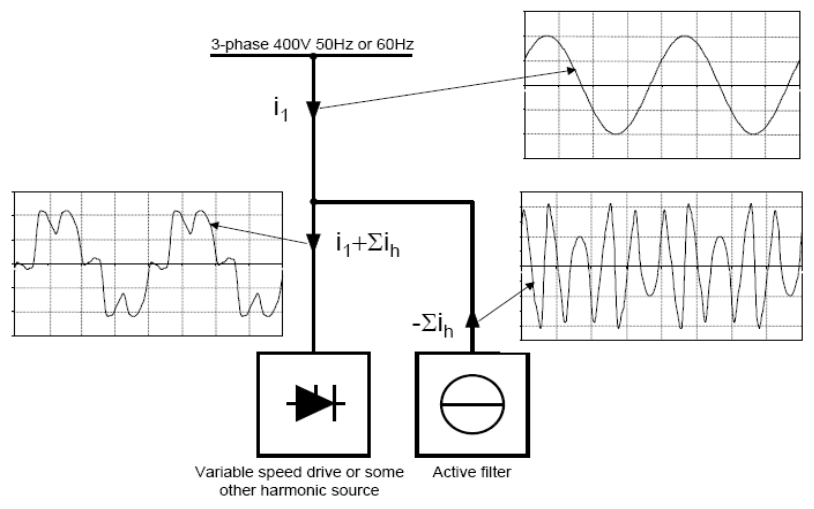

Fig.3 The effect of connection of an active filter parallel to the harmonic load 
Whenever we are connecting a shunt active filter parallel with a harmonic or/ and reactive load, that harmonic or/and reactive part of the load will be compensated by the filter as shown in the figure 4.2. and the network is loaded by almost fundamental current only. It should be noted that the output current of an active filter has a continuous spectrum of all harmonics due to the accuracy of the control system. Therefore in the network current there are still some harmonic currents.

A three-phase system has been selected to study the performance of the APF system. Comparison and shows the compensation principle of a shunt active power filter. APF injects a current equal in magnitude but in phase opposition to harmonic current. The heart of the APF system is the IGBT based Voltage Source Inverter (VSI). A dc capacitor is used to deliver power for the VSI. For the successful operation of APF, capacitor voltage should be at least $150 \%$ of maximum line-line supply voltage.

\section{APPLICATION OF STATIC SHUNT COMPENSATORS}

Usually a STATCOM is installed to support electricity networks that have a poor power factor and often poor voltage regulation. There are a number of other uses for STATCOM devices including, wind energy voltage stabilization, and harmonic filtering. However, the most common use is for voltage stability.

Shunt compensation technique is to deliver for the flaws in the series technique, primarily in the voltage control due to its location in a system. Table 4.1 shows applications of some different types of shunt compensators including the corresponding short-circuit level and the transmission phase angle.

A. Mechanically Switched Reactor (MSR) and Mechanically Switched Capacitor (MSC) devices are part of the shunt compensators family. As seen from the table, SVC and STATCOM show better performance in the applications with respect to other main devices.

\section{B. COMPARISON BETWEEN STATCOM AND SVC}

In terms of its applications it can be seen that under shunt compensation, for voltage control and reactive power control, SVC and STATCOM are faster than other static compensators. it can be seen that the STATCOM can provide both capacitive and inductive compensation and is able to control output current over the rated maximum capacitive or inductive range independent of the ac system voltage. That is, STATCOM can provide full capacitive output current at any system voltage, practically down to zero, in contrast with the SVC which can supply only diminishing output current with decreasing system voltage as determined by its maximum equivalent capacitive admittance. Furthermore STATCOM may has an increased transient rating in both inductive and capacitive operating regions, whereas the conventional SVC has no means to transiently increase the Var generation since the maximum capacitive current it can draw is strictly determined by the size of capacitor and magnitude of the system voltage.

The available transient rating of the STATCOM is dependent on the characteristics of power semiconductors used and the junction temperature at which the devices are operated. The ability of the STATCOM to produce full capacitive output current at low system voltage also makes it more effective than the SVC in improving the transient (first swing) stability. This is because the STATCOM is able to maintain full compensating current at depressed line voltage occurring during the first swing as a result of sharply increasing electric power transmission. The inherent capability of the STATCOM to generate as well as to absorb reactive power makes it eminently suitable for power oscillation damping and hence power control.

\section{RESULTS AND DISCUSSION}

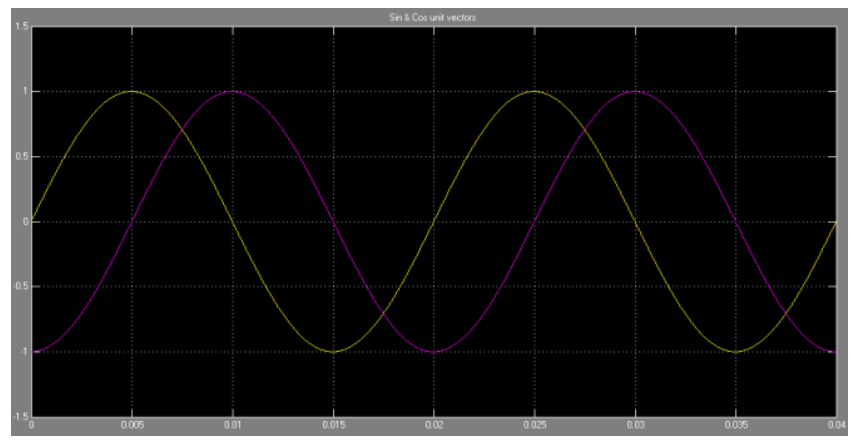

Fig .4 Sin and Cos unit vectors 


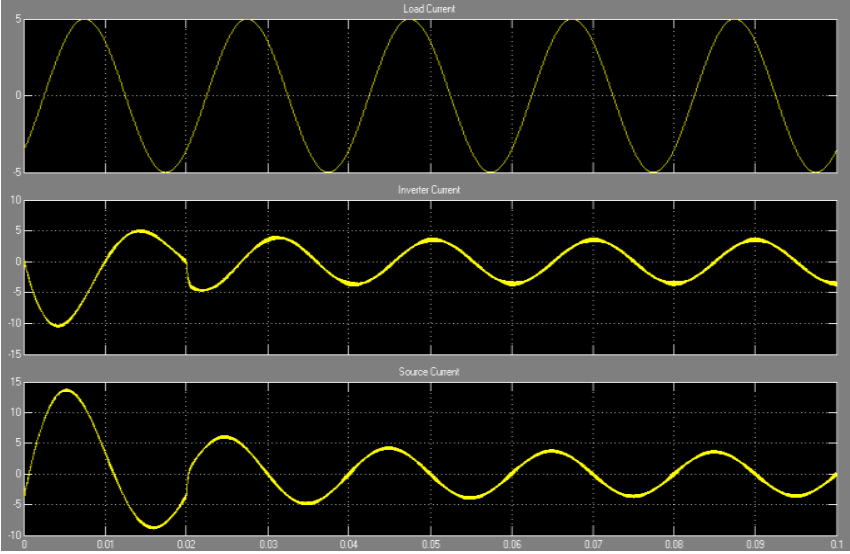

Fig 5 Load, Inverter and Source current of STATCOM for Reactiveload

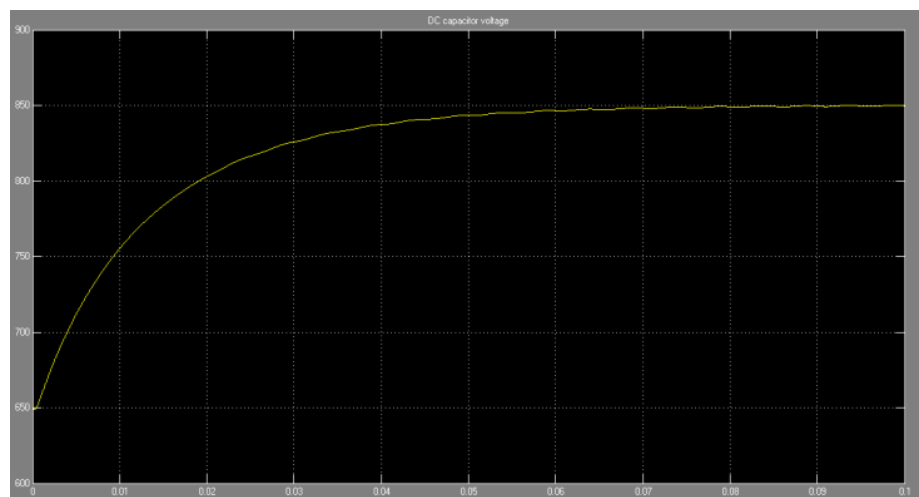

Fig 6 Capacitor Voltage

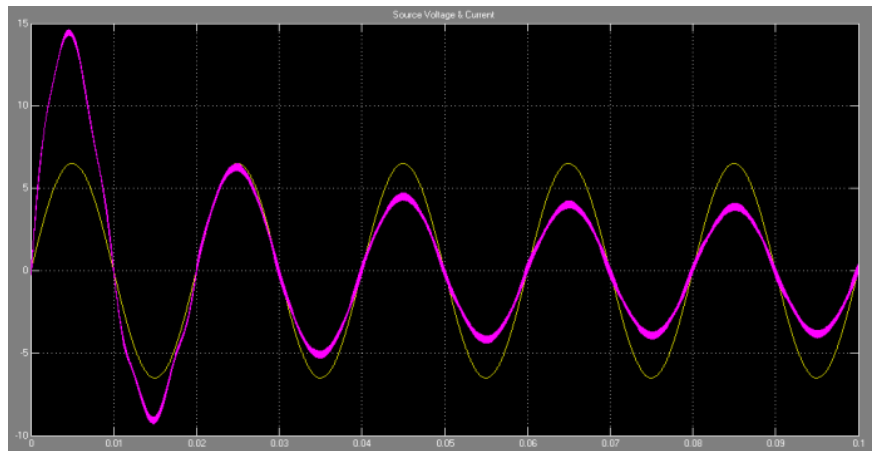

Fig 7 Source voltage and current supplied for a Harmonic Load of THD 13.42\%

\begin{tabular}{|c|c|c|c|c|c|}
\hline \multirow[b]{2}{*}{ CASES } & \multicolumn{3}{|c|}{ THD in $\%$} & \multirow{2}{*}{$\begin{array}{c}\text { Power } \\
\text { factor } \\
\text { Angle } \\
\text { in }^{\circ}\end{array}$} & \multirow{2}{*}{$\begin{array}{c}\text { Angle } \\
\text { after } \\
\text { comp } \\
\text { ensati } \\
\text { on }\end{array}$} \\
\hline & $\begin{array}{l}\text { Load } \\
\text { Curren } \\
t\end{array}$ & $\begin{array}{c}\text { SPW } \\
\text { M }\end{array}$ & $\begin{array}{c}\text { SVPW } \\
\text { M }\end{array}$ & & \\
\hline $\begin{array}{c}\text { Harmonic } \\
\text { s Load }\end{array}$ & 13.42 & 5 & 4.7 & 0 & 0 \\
\hline $\begin{array}{c}\text { Reactive } \\
\text { Load }\end{array}$ & 0 & 5.07 & 4.577 & -70 & 0 \\
\hline $\begin{array}{c}\text { Harmonic } \\
\text { s and } \\
\text { Reactive } \\
\text { Load }\end{array}$ & 10.25 & 5.041 & 4.564 & -45 & 0 \\
\hline
\end{tabular}


From the above table, we can say that Space Vector Pulse Width Modulation is better than Sinusoidal Pulse Width Modulation. THD is improved much for SVPWM. THD is within IEEE standards and power factor is near to unity by the application of STATCOM in a power system network

\section{CONCLUSIONS}

The basic principle and controller design of a STATCOM was studied in detail in the present work. The simulation studies helped in understanding the principles involved in STATCOM development. This chapter gives a gist of the complete work and provides inputs for possible future studies in this area. In the present study, the Synchronous Reference Frame based STATCOM was simulated and the results studied. The study shows that the system gives good dynamic performance under varying load conditions. Whereas the reactive current compensation gives highly favorable results, the harmonic performance depends largely on the load. Harmonics may not be completely compensated owing to the limitations posed by the inverter which can produce voltages only in a time-averaged sense.

\section{SCOPE FOR FUTURE WORK}

Further work on STATCOM can be aimed at improving the speed of response, implementing improved inverter techniques, trying out more improved compensation techniques and the like. Some possible things that can be done are listed here. Changes can be brought about in the implementation of the controller so as to speed up the response time. The system may be modeled as a second order system and the responses can be studied. The inverter topology may also be changed. Three-level inverters may be studied. Thus, STATCOM is an area where there is a wider scope for further studies

\section{ACKNOWLEDGMENT}

The authors would like to thank the authorities of Ghousia College of Engineering, Ramanagaram for all the cooperation and encouragement in carrying out this work.

\section{REFERENCES}

[1] SudeepKumar R, Ganesan P Centre for Development of Advanced Computing, Trivandrum,India,

[2] “25OkVA Unified Power Quality Controller"-2006 IEEE.

[3] J. Chelladurai, G. Saravana Ilango, C. Nagamani, and S. Senthil Kumar, "Investigation of Various PWM Techniques for Shunt Active Filter", International Journal of Electrical Systems Science and Engineering Volume 1 Number 2

[4] Unnikrishnan A.K, Senior Member IEEE, Aby Joseph, and Subhash Joshi T.G., Member IEEE Centre for Development of Advanced Computing (C-DAC) Trivandrum, Kerala India, "Three-level Converter based Active Filter for harmonic compensation of 4MW Induction Furnace". PEDES , 2007 IEEE

[5] Iswaran Sothandara Kumaran, Department of electrical and computer engineering Curtin university of Technology, "flexible alternating current transmission systems: static synchronous compensator (STATCOM)

[6] P. S. Sensarma, Student Member, K. R. Padiyar, Senior Member, V. Ramanarayanan, Analysis and Performance Evaluation of A Distribution STATCOM for Compensating Voltage Fluctuations” PE-065PRD (I 0-2000)

[7] Moleykutty George and Kartik Prasad Basu, "Three-Phase Shunt Active Power Filter" American Journal of Applied Sciences 5 (8): 909-916, 2008

[8] Science Publications ABB Switzerland Ltd Advanced Power Electronics, "STATCOM Converter solutions for reliable and stable grids" 